\title{
LA REDIFINICIÓN DE EUROPA Y LA TECNOLOGÍA DE LA CREATIVIDAD
}

\section{REDEFINING EUROPE AND THE TECHNOLOGY OF CREATIVITY}

\section{AUTOR}

\section{Julián Plana Pujol}

Profesor honorífico y Director del Seminario de Creatividad Social en la UCM. Profesor Invitado en la Cátedra de Proyectos de la Escuela Técnica Superior de Ingenieros Industriales (UPM).

plana.j@apmadrid.es.

\section{RESUMEN}

Europa puede ser entendida, como dijera Metternich de Italia, como una expresión geográfica o como una patria común de los europeos. Cuando se viaja por ella, se pueden percibir elementos de unión (y también, por qué no decirlo) de desunión) que deben prevalecer a la hora de construir el futuro de la Patria, convertida en tierra no de padres sino de hijos. La creatividad con sus amplias herramientas y recursos ha de ponerse al servicio de la inteligentzia para conseguir cementar las tendencias disgregadoras que acechan a este proyecto común, que en breve poseerá una moneda única.

\section{PALABRAS CLAVE}

Creatividad - Europa - Ideas - Cultura europea - Tormenta de ideas.

\begin{abstract}
Europe can be understood, as Metternich said of Italy as a geographical expression or a common European home. When traveling through it, you can receive fasteners (and, why not say) of disunity) should prevail when building the future of the Fatherland, land converted to parents but not children. Creativity with extensive tools
\end{abstract}


and resources has to be of service to the intelligentsia to get cement the divisive tendencies that threaten this joint project, which will soon possess a single currency.

\section{KEY WORDS}

Creativity - Europe - Ideas - European Culture - Brainstorming.

\section{ÍNDICE}

1. Bruselas, 1954. "Jusque /'action!".

2. Los años nuestros.

3. El crisol frío.

4. El "Efecto bicicleta" o el "Efecto Von Osten".

5. Imaginación aplicada sistemáticamente.

6. La tecnología de la inteligencia.

7. Mente y Grupo.

8. Cultura y Acción.

8.1. Evolución y mutaciones.

8.2 Individuo y Grupo.

9. Las formas creativas.

10. Ingenuidad y Acercamiento.

11. Psicocibernética y Recreación.

11.1 Los métodos de redefinición.

11.2 Métodos de reestructuración.

11.3 Las técnicas de aparición de "ideas".

12. Nuevamente, la importancia de las formas creativas.

13. La redefinición de Europa y la tecnología de la creatividad.

14. La redefinición de Europa.

15. "Reunión en la cumbre".

16. Bibliografía. 


\section{Bruselas, 1954. "Jusque I'action!"}

Durante el verano de 1954 llovió mucho en toda Europa o me lo pareció a mí. Lo digo porque la recorrí en gran parte y en una de aquellas primeras vespas verdes, con la única protección de una de aquellas trincheras, que quizás usted recuerde, que se llamaban "comando" y que también eran verdes y no precisamente muy impermeables.

En Agosto llegamos a Bruselas, aquellos tres jóvenes catalanes, y nos encaminamos al camping "Europa Unida", situado en una zona de viviendas unifamiliares con cuidados jardines-huertos, de la que acabó por ser dulcemente expulsado en 1967 por la irresistible y dulce presión del creciente valor del terreno.

No era, como ya sabíamos, un "camping" convencional, ni siquiera para aquellos años Un mástil realmente muy alto ofrecía al viento la bandera de la E verde y la U blanca desde la que se desprendía en vertical un empavesado en el que se alineaban, en orden alfabético, pequeñas banderas de los países de los acampados. No había ni tenían una bandera española, pero al día siguiente estaba allí, entre las otras, confeccionada al amanecer por unas chicas. Sin duda al amanecer, porque aquélla y todas las noches nos acostábamos muy tarde, después de horas alrededor de una fogata, si por casualidad no llovía, o en el abigarrado chalet, que todavía pude hacer conocer a mi mujer pocos días antes de que se desmantelara para siempre. Era una construcción de madera atestada de recuerdos y obsequios; con unas butacas producto no exactamente de lo que llamamos bricolaje, sino de una especie de artesanía barroca y libre, inexplicablemente seguras y muy cómodas.

Por cierto, el 67 la bandera era ya la de las estrellas en circunferencia. La del fondo verde recortado en "E" por la "U" horizontal blanca se decía que eran los calzoncillos de Churchill puestos a secar sobre una pradera. Se hubiera dicho que todo el homenaje popular que merecía el político del puro por su famoso discurso de 
Septiembre del 46 en Zürich, instando a la integración europea, era ese mal chiste.

¿En que idioma hablábamos? Quizás preferentemente en francés; algunos alemanes e ingleses y, sólo muy tímidamente, nosotros utilizábamos el latín; el inglés... Es curioso pero no recuerdo que se sintiera la necesidad de una lengua común, ni esto era tema de conversación. Nos entendíamos. Tampoco recuerdo, y creo que nunca supe, las ideas políticas con siglas, de los demás. Ni ellos, las nuestras. Europa nos parecía una buena idea.

En Bruselas era la Grande Kermesse y pasábamos a veces la tarde en el brillantísimo y enorme recinto de las atracciones, pero invariablemente nos amanecía imaginando Europa Por ejemplo, discusiones densísimas incluso sobre la futura sede de la capital: Hamburgo o Lübeck, Estrasburgo, Viena, sobre todo Praga... Nosotros proponíamos Lisboa, proyectando nuestra vieja idea federalista y periférica (y nuestra frustración y nuestras especulaciones de historia-ficción sobre una España renacentista con Lisboa como capital).

El día que seguimos viaje llovía masivamente, pero nos esperaban en Amsterdam y Otterloo Vermeer, Rembrand, Van Gogh, Mondrian,.. Salieron todos de sus tiendas para ayudarnos y despedirnos, Nunca podré olvidar a un alemán altísimo y fornido, el tamaño de cuyas botas era una de nuestras admiraciones por él, vestido sólo con una especie de poncho de hule y aquellas botas, con el cabello chorreándole sobre los ojos, agitando su gran mano y gritando en su francés bárbaro "Jusque l'action!" "iHasta la acción!".

"Nacionalismo" europeo, sí, Nacionalismo integrador, de formación.

Los corazones debían hacer humear nuestras ropas majadas, mientras con el rostro brillante de lágrimas y de lluvia nos encaminábamos a Holanda, otro país de nuestra nación. 


\section{Los años nuestros}

Siguieron los años cincuenta. Budapest. Llegaron aquellos sesenta. Praga, El 67 fue el año de El desafío americano de J.-J. Servan-Schreiber y el año antes de Mayo; de "el poder de la imaginación" a "la imaginación al poder" cuando el miedo se estaba apoderando de Europa y todos pedíamos imaginación, aun antes de notar llegar a los japoneses, La "crisis del petróleo"; la crisis, en definitiva, acabadas los "milagros". Entre tanto, el Muro, la OTAN, El Pacto de Varsovia, "occidente" (que nosotros creíamos que era un mito sólo "aquí y entonces").

Nos consolábamos pensando que también la Revolución necesitó medio siglo de Enciclopedia o que en la biografía de André Citroën se cuenta que un día estaba enseñando su fábrica a un grupo de visitantes y uno le preguntó en cuanta tiempo se hacía un coche; Citroën respondió que habían llegado a terminar uno en 23 minutos y se oyó una voz en el grupo que decía "ése debe ser el mío".

Y lo cierto es que Europa no cesaba de acercarse, desde los últimos cuarenta, Salvador de Madariaga e Indalecio Prieto nos representaron (lo doloroso fue que ambos eran -ni siquiera se decía "estaban"- exiliados) en la formación del Consejo de Europa. El 50, Robert Schumann había presentado el plan germano-francés "abierto a los otros países europeos y en asociación con las Naciones Unidas", que iniciaba la Comunidad Europea del Carbón y del Acero. Cinco años después del fin de la Guerra, nada menos que el carbón y el acero y Francia y Alemania. De morir por el Ruhr a vivir en Europa.

Pero la Asamblea Francesa (a cuyas cercanías habíamos acudido aquel verano del 54 para saludar la paz en Indochina, desgraciadamente al mismo tiempo que otros grupos con otras intenciones) había rechazado el proyecto de una Comunidad política. Por lo que el genio, los genes europeos tuvieron que afirmarse en el flanco económico. El 25 de Marzo de 1957, en Roma, se firma la Comunidad Económica 
Europea, El 58, la CECA resiste un fuerte momento crítico... Se había "despegado" y cada vez más uníamos nuestras miradas en el mismo sector aun impreciso del horizonte.

Es preciso rendir, pues, homenaje a la llamada "Europa de los Mercaderes", ya que donde no hay beneficios parece haber "maleficios" y me temo que donde no existe la competencia florece la incompetencia. Lo que no quiere decir que éste sea un continente de toneladas de mantequilla sino la nación de unos millones de seres humanos que, por otra parte, consumimos cada vez menos mantequilla.

\section{El crisol frío}

Pero "nuestros años" pasan. ¿Y qué ocurre (o no ocurre)? ¿Por qué los componentes de Europa se agitan en el crisol sin que se produzca la síntesis que esperábamos?

Es posible que falte aún temperatura, que falten algunos elementos - gran parte de la Europa Central y la del Este, "hermanos separados" de una nueva versión de las "guerras de religión" en la Europa actual- y que no acudamos a la tecnología intelectual adecuada, la Enciclopedie de hoy, y que por ello no conseguimos imaginar cómo seremos dentro de 20 ó 30 años, coma advierte Francesco Alberoni.

(Si se me permite por un momento el zoom hacia un detalle de la fotografía, no se si no nos está sucediendo algo muy parecido Pirineos abajo. En Febrero del 85, un grupo variopinto de intelectuales se reunió en Gerona para intentar una "redefinición de España". No se pasó de un pintoresco prólogo y la prensa de casi todas las tendencias se cebó incomprensiblemente en el objeto de la reunión.)

Y uno de los principios y uno de los sectores de técnicas más interesantes de la actual Creatividad es precisamente la Redefinición. Las definiciones caducan, como los yogures, pero pueden perpetuarse, también coma los yogures, a través de la 
redefinición, utilizando fermentos aun activos, aun no pasados (pero que pueden "pasarse" y acabar por ser inútiles).

\section{El "Efecto bicicleta" o el "Efecto Von Osten"}

George Prince dice que cuando los individuos trabajan en grupo, hay fuerzas poderosas que actúan para neutralizar el valor de estimulo de la creatividad. Otro hombre dijo: "El problema del hambre en el mundo está completamente resuelta. Si no se pone remedio es sencillamente par una razón: porque, al parecer, no queremos". Pocos meses, casi semanas, después de decirlo, moría a balazos por la espalda y no se sabe quién, en realidad, disparó aquel rifle de mira telescópica, incluso después de la que ha sido sin duda la investigación criminal más costosa y más controvertida de la Historia; fue el presidente más joven de su país y se llamó John Fitzgerald Kennedy.

Y no podemos seguir negándonos a confrontar los grandes temas sólo con el pretexto del "día a día": subvenciones inhibitorias siempre de la creatividad y muchas veces contradictorias, presupuestos y excedentes. Nos vamos a caer de la bicicleta por mirar a la rueda o nos vamos a perder, o ambas cosas, porque todos hemos experimentado que se va hacia donde se mira. Miremos, pues, hacia donde queramos ir. Averiguándolo previa y científicamente, puesto que si no "vemos" Europa mal puede desencadenarse (que es, obviamente, una palabra positiva) el efecto Von Osten, según el cual los resultados suelen tender hacia las expectativas.

No confiemos, perezosamente, en el "sentido de la Historia", cuando ya la mecánica cuántica nos ha mostrada que ello es no-determinante, "el campo de todas las posibilidades". 


\section{Imaginación aplicada sistemáticamente}

La Redefinición supone momentos no exentos de cierta angustia. Cuando se sospecha que la imagen que proyectamos en una pantalla no está del todo enfocada (que es cuando decimos precisamente que le falta "definición") y actuamos sobre las lentes, suelen producirse imágenes aun más borrosas; alguien dice "Pero si ya se veía bien"; otro exclama "iDónde vas!". Se mejora y se empeora provisionalmente, pero se tiene la idea -porque ésta sí debe ser clara- de que lo hacemos para enfocar la imagen, para redefinirla al máximo. Y casi siempre lo conseguimos.

¿Sabemos realmente qué es Europa? ¿La vemos clara? ¿La tenemos enfocada en nuestra imaginación? ¿Apreciamos distintivamente sus futuros detalles, límites, relación con el entorno, físico e histórico? Pues de la misma manera que la tecnología de los microprocesadores puede ayudar a efectuar un complicado cálculo de miríadas de variables que llevaría años de otra manera, una vez lograda la adecuada programación, la Creatividad puede y debe ayudarnos decisivamente a redefinir todo aquello que "no acabamos de ver claro".

\section{La tecnología de la inteligencia}

La Ciencia soporte de esta Tecnología es la que podríamos llamar Ciencia de la Inteligencia, ¿Existe tal cosa? Efectivamente, las diversas Ciencias estudian las distintas ordenaciones de los modelos (Física, Química, Biología, Ecología, etc.) pero, ¿que Ciencia estudia la ordenación?

Para Aristóteles, la Metafísica, la Ciencia del Ser, el "movedor inamovible". Para Platón, la Dialéctica, para "alcanzar la idea de bien". Posteriormente, se pensó en la Moral. De nuevo, en la Dialéctica. Más modernamente, en el lenguaje, su significado y estructuras. 
Ahora bien: ¿cuál es el elemento común a las diversas Ciencias? La Inteligencia es aparentemente lo único interdisciplinar: nosotros.

Es hoy indudable que existe un soporte fisiológico y una especie de complicada electroquímica de la Mente, del comportamiento neuronal, de la asociación y combinación de ideas, de la relación grupal, de las actitudes, de los ambientes, las tendencias, la "modificación". Hablamos con soltura del subconsciente y también del "subconsciente colectivo". Y existe un creciente interés por lo que ampliamente conocemos como Ciencias Sociales. Ocurre, sin embargo, que se parece creer que la tecnología final de las Ciencias Sociales es el Conocimiento, todo lo más la Educación, quizás la manipulación, en vez de la Creatividad.

Incluso aquéllos entre nosotros que anteponen, supongo que innecesariamente, la Religión a la Ciencia estarán de acuerdo en que, si Dios "creó al hombre a su imagen y semejanza", ello no quiere decir que Dios tiene dos piernas y brazos, una nariz, vello en las axilas. ¿Cómo es Dios? Dios es creador.

Posiblemente, "el fin último del conocimiento no es la sabiduría, sino la acción", como dijera Herbert Spencer, pero diríase que éste no es un pensamiento "elevado"; la sabiduría sí es admirable porque, además, conduce como se sabe a la prudencia, de la que ya dijo La Rochefoucauld "Se elogia la prudencia y sin embargo es una virtud incapaz de protegernos ante cualquier acontecimiento". La acción es para los bárbaros o para unos cuantos entre nosotros que, bien o mal, nos sacan las castalias del fuego ( $y$ a los que debemos "criticar" severamente, porque éste es nuestro papel de "intelectuales"). Los "mercaderes" o los políticos excepcionales, los creadores de riqueza o de condiciones, incluso los artistas innovadores en cada momento.

Tengamos el valor de darnos cuenta de que la educación, sin creatividad, forma al hombre para ser parásito de la Sociedad. Tal "educación" no es más que un módulo reproductivo del Sistema, degenerativo por endogamia funcional, que arrastra en su 
degeneración al Sistema mismo, en vez de ser el tenaz manantial, imprescindible para el cambio efectivo y el auténtico crecimiento.

La Creatividad, la Tecnología de la Inteligencia, se propone la sistemática superación, redefinición o desaparición ("solución") de los problemas abiertos. Que son casi todos. Estamos acostumbrados a reducir la idea de problema a los aritméticos de nuestra infancia. Creemos que sólo hay una solución, que el procedimiento es también único y "el del libro" (siempre hay "un libro") y que además la solución ya existe en alguna parte (en el "libro del maestro", en el Pasado, en la ortodoxia de nuestras "ideas" preexistentes).

Es preciso insistir en que hay muy pocos "problemas cerrados". Incluso cuando se dice que "2 y 2 san 4", se pasa por alto que pueden ser "22" o que, si se trata de dos parejas de seres humanos de distinto sexo, al cabo de poco tiempo pueden ser "5" ó "6" ó más; y si se trata de conejos... Por el contrario, podría tratarse de figuras de material maleable (la "plastilina" de los escolares, por ejemplo) y resultar fácilmente "1"; o de metal y acabar también en "1" aplicando calor (no estaba prohibido, en el problema) o de cristal y caer al suelo.

¿Cuántos puntos equidistan entre sí? ¿Tres? ¿Y si acudimos a otro plano, a otro nivel? iAh, claro! Pero es que, como decía Ortega, la "filosofía" es un problema de nivel, Si queremos ver lo que nos espera tras la curva del río habremos de llevar la balsa a la orilla y esforzarnos en subir a la calina, porque esta aceleración que notamos puede indicar un serio peligro. En una película de dibujos animados, Mickey, Goofy y los otros caminan por territorio desconocido; ellos no lo advierten pero lo que creen que son simples irregularidades del terreno son las huellas de un gigante; el espectador, desde otro nivel, sí. Se trata, pues, de superar el problema; para ello, es necesario un determinado esfuerzo. La Creatividad es precisamente el conjunto de técnicas para la determinación de dicho esfuerza. 
Y es básico mantener esta actitud a la superación (en vez de a la pretendida "solución" convencional de los problemas, mezcla de desconfianza sistemática hacia los planteamientos dados e incluso hacia el lenguaje), manteniendo la facilidad de cambiar de plano o de dimensión. Una analogía védica es que es inútil pretender barrer la oscuridad de una habitación; es preciso y basta con encender la luz o permitir que entre por la ventana.

\section{Mente y Grupo}

El cerebro contiene $10^{10}$, diez mil millones de neuronas. Cada una capaz, parece ser, de sostener unas mil sinapsis, vehículos de asociación.

Por cierto: el promedio de pérdida diaria se calcula en unas cien mil neuronas. Aunque, por lo que sabemos, no se recuperan, es posible que las sinapsis salven parte de la información trasladándola antes de "caerse". El alcohol, el tabaco y las otras drogas, la escasez de oxígeno y la "falta de ejercicio" mental son algunas de las causas de cifras más altas - que pueden ser muy altas - en la pérdida de neuronas.

Pero la Mente individual no consiste sólo en el cerebro y sabemos aun muy poco sobre éste, así como sobre el sistema nervioso, linfático, las increíbles secreciones glandulares...

$\mathrm{Ni}$ siquiera el individuo es "solamente" él mismo. Llegamos hasta donde llegan nuestras relaciones intrasociales (Plenge). Pensemos en la falta de desarrollo física, hormonal, etc., de los "niños salvajes".

Es curioso que ahora el concepto de "ordenador" esté ayudando a establecer un modelo de la mente. Si no se trabaja más en este campo de la investigación científica (en el que figuran nombres españoles como Ramón y Cajal o Rodríguez- 
Delgado), podríamos llegar a imaginar la inteligencia como una inteligencia artificial natural.

\section{Cultura y Acción}

El objetivo de la investigación es el descubrimiento. El de la creatividad es la invención (de obras de arte, de máquinas, de conceptos, de sistemas, etc.).

Descubrimos lo que está ahí. Inventamos, diseñamos, proyectamos, lo que na estaba pero -aunque podía no parecería- era posible; diríase que nos estaba esperando en alguna parte.

Pero incluso en la Física se produjo la polémica entre los que la basaban en la observación y los que en la invención teórica e hipotética y el mismo Einstein, en su famosa carta a Popper, defiende la Física especulativa (Ortega, antes de conocerse esta carta, llamaba a Einstein "relacionista").

La Creatividad es pues el puente entre lo que se llama, restrictivamente, realidad y lo que se llama, por el contrario exageradamente siempre, utopía.

Descubrimientos e invenciones, acumulados y depurados, combinados y adaptados, vividos, es lo que llamamos Cultura, Aun cuando se hable de "cultura francesa", por ejemplo, la Cultura es única, creciente y autodepuradora. Diferente tema son las civilizaciones temporales (incluida la nazi), los tics nacionales a, en un sentido limitado pero muy respetable, la aportación y los matices étnicos o locales a o de la Cultura que, cuando son exclusivistas o perturbadores, son simple "civilización" (tomada la palabra en ese sentido que, afortunadamente, no es el único).

Y Cultura es, por otra parte, cultivar, trabajar; no, "saber", simplemente. "Ser culto" es "hacer cultamente" o no es casi nada. Y lo que es grave: trabajar no-cultamente 
es potencialmente estéril y nocivo.

Sensu contrario, la única Acción realmente estimable es la que contiene una parte apreciable de investigación y de creatividad. Toda Acción, todo Trabajo, ha de contemplar el Cambio como parte integrante.

\subsection{Evolución y mutaciones}

Efectivamente, la Evolución está ejemplificada en el cambio. Los paleontólogos nos dicen que lo que se llama comúnmente evolución (en la que pensamos corrientemente como algo sin solución de continuidad) es una sucesión de mutaciones, de transformaciones.

La Transformación es el gran juego de las especies pero, sobre todo, del ser humano. La aventura, el riesgo, la adaptación dialéctica al medio, la aceptación de desafíos, constituye lo que llamamos la vida.

\subsection{Individuo y Grupo}

En cuanto a nosotros, cada uno es único e irremplazable. No hay dos combinaciones idénticas de código genético, experiencias subconcienciadas, educación asimilada, conocimientos - con sus interrelaciones- y relaciones con los otros, que son asimismo individuos diferentes y "tomados" de diferente modo. Ni siquiera la misma combinación, es decir, el mismo ser humano- resulta estimablemente parecida a sí misma, al ser "puesta en juego" creativamente en dos ocasiones.

(Estamos hablando del individuo; no, de la "Persona"; es decir, no de la teatral máscara "per sonare" superpuesta.)

El grupo es un individuo de nivel superior (para empezar, con más neuronas, más 
posibilidades de sinapsis, distintas experiencias y educaciones; muchos más, diferentes y complementarios conocimientos), si dispone de las formas, propósitos y técnicas del pensamiento en común; es decir, si consigue actuar como una individualidad o "totalidad dinámica" (Allport).

\section{Las formas creativas}

Tan importante como en los cuerpos o en el arte y en la ciencia, son esenciales las Formas en las relaciones, por más que se desprecien y se enmarañe la zafiedad en las recesivas y a veces desesperadamente prolongadas épocas no-clásicas.

Un ejemplo de forma imprescindible es el estricto aplazamiento de la evaluación $-\mathrm{y}$ tanto más de la "crítica"- a sensiblemente después de una fase de ideación (aunque obviamente antes de las decisiones previas a la acción).

Otro, como asimismo veremos, es la respuesta fragmentada, consistente en no aprobar o desaprobar en bloque una proposición, ni siquiera una afirmación de otro a ser posible; sino en responder con los factores positivos y los negativos descubiertos, permaneciendo abierto a añadir o restar $y$, sobre todo, a actuar en los "negativos", para llegar a una conclusión lo más sinceramente objetiva y constructiva posible.

Resulta claro que estas formas "despersonalizan" la relación, integrando a cada individuo en una unidad de orden superior, con todos sus valores (incluidos, por supuesto y sobre todo, precisamente los diferenciales).

El grupo no es un equipo, con especializaciones y puestos definidos y, si bien se comporta como totalidad dinámica, no es antropomórfico (es el creador individual el que debe ser "grupo móríico" puesto que, en frase de Unamuno, "contiene muchedumbre"). 
No es una asamblea; tampoco es una comisión, Un político español dijo aquello de "si quiero que un problema se resuelva lo encomiendo a un hombre; si quiero que no se resuelva, a una comisión", Y se dice, como saben, que un camella es un caballo dibujado por una comisión.

Porque el grupo no esta formado por "personas" sino por individuos. El grupo carece de lo que llamamos "jefes", "directivos", "superiores" o "inferiores". Se convierte pronto en un individuo plural, al objeto de la reunión (que no tiene por qué ser una reunión "física", por otra parte); un individuo cultísima, polifacético, plurisexual, ágil e ingenioso; porque se multiplican las experiencias, conocimientos y habilidades de cada uno por los de cada otro, relacionándose más y más fluidamente entre sí las experiencias, habilidades y conocimientos de todas, como si se tratara de cargas neuronales de un solo cerebro funcional.

Solo es una comisión, una junta, una "reunión" al uso, sobre todo, porque nadie teme "quedar mal", "decir una tontería" en un momento dado; está ausente la prudencia, virtud que -insisto- tiene sin duda otras aplicaciones.

Es muy frecuente que al fin de una reunión creativa, que siempre se hace corta (produciéndose generalmente una sorpresa al comprobar que ha pasado mucho más del tiempo previsto), los participantes se muestren asombrados de haberse oído decir cosas "que no sabían". ¿Es que "ha sonado la flauta por casualidad"? Precisamente los hindúes dicen que para ser creativos debemos relajarnos, ser -pero sólo en cierta manera- pasivos, convertirnos en "la flauta de Khrisna".

Einstein excitaba a sus alumnos diciéndoles que utilizamos usualmente sólo el diez por ciento de nuestra capacidad mental. ¿Qué sabemos, en realidad, de nuestro subconsciente? Al menos, que las técnicas creativas lo explotan en gran medida. Ese noventa por ciento de nosotros mismos también come, ¿no? Pues que trabaje. 
Por otra parte, en la primera reunión de un grupo creativo suele hacerse una comprobación sencilla: se pide a cada participante que anote ideas relacionadas con un concepto determinado. Yo viví una ocasión en la que, al hacerse una lista general de las ideas producidas, aunque había muchas coincidencias que fueron depuradas, el grupo produjo 277 ideas diferentes (algunas muy sugerentes), lo que multiplicó por 4,2 la aportación individual más importante y por 8,1 la aportación promedio. Sobre la base de estas 277 ideas primeras, se hicieron nuevas listas separadas y se consiguieron otras 158, lo que multiplicaba por 6,58 la mejor aportación individual y por 12,16 la aportación promedio. Y entre ellas había ideas francamente originales. Pero ésta no fue la única incursión en la totalidad del grupo. Se pidió también a sus participantes que anotaran los libros leídos en los últimos dos meses, que países conocían, dónde habían nacido; que libros concretas o películas u obras teatrales, etc., les habían impresionado realmente en toda su vida... La fabulosa riqueza encerrada -lamentablemente encerrada - en aquel grupo de estudiantes era muy superior a la que se dice que encierran los restos del Titanic. Sólo era necesaria una tecnología de su explotación. Y un objetivo, aunque fuese provisional.

En cuanto a la calidad de las ideas producidas por el grupo, frente al famoso "genio" de las raras individualidades, he de testimoniar que, al principio del ensamblaje de un grupo, los que se tienen por "los" inteligentes se sorprenden visiblemente de "lo" inteligente de las aportaciones de los otros.

\section{Ingenuidad y Acercamiento}

Cuando se dice, en Creatividad, que el acercamiento a los problemas debe ser "ingenuo", se quiere decir original, no originado (no otra cosa quiere decir, etimológicamente, "ingenuo"), libre, no sólo de prejuicios sino incluso de preplanteamientos. Un acercamiento de amable extraterrestre. 
Por otra parte, el acercamiento debe no detenerse en la superficie del problema. Debemos "hacernos uno" con el problema y éste con nosotros (seamos individuo o grupo).

\section{Psicocibernética y Recreación}

Una aplicación especialmente interesante es la reprogramación (hablando en términos de ordenadores) individual, grupal, empresarial o social; sustituyendo por motivaciones inteligentes, deliberadamente causadas, parte sustancial de la programación acumulada por el azar, "meteorológica", preexistente.

Otra, la creación publicitaria o recreación del producto o servicio, el grupo político, el modelo social, etc., para imaginarlo, reconstruirlo, en la civilización del momento y el lugar.

\subsection{Los métodos de redefinición}

Naturalmente hay que contar con unos primeros "objetivas", por criticados y modificados que resulten en el proceso.

Empezando pues por el principio, la Orientación por Objetivos es una actitud y, por extensión, la técnica de y para estimular esta actitud. Se trata de reconocer:

- Necesidades (todo aquella que pretendemos conseguir),

- Restricciones (lo que no deseamos que ocurra),

- Obstáculos (lo que nos impide lograr lo que queremos),

- Facilidades (lo que nos ayuda a lograrlo) y

- Fases (que pueden suponer rodeos a las restricciones o a los obstáculos, esperas, elaboraciones, etc.).

Para inmediatamente criticar (sobre todo esas restricciones: ¿podemos aceptar 
alguna, incorporarla, aprovecharla, variarla, etc.?), establecer objetivos parciales para fases factibles, marcar tiempos, costos, etc., y preparar un planning, pert u otros gráficos útiles.

Otros Métodos de Redefinición (pero en esta conferencia no pretenderemos mencionar todas las técnicas creativas) son la Trituración de Dimensiones, que consiste en pulverizar para redefinir; una técnica tan antigua como la alquimia o la alfarería en la que la "mano de mortero" son las temibles palabras "¿Y si...?", iniciando una exhaustiva serie de preguntas. El uso sistemático de Analogías, Metáforas y, en definitiva, la Fantasía, la Visualización mental, el Sleep-Vríting (la "escritura automática" de los surrealistas, cuya técnica se aplica a la imaginación de, efectivamente, una realidad de otro nivel). La Serendípity. Los Juegos de Alternativas, poniendo entre interrogantes todas las "dimensiones" (Ios datos, cada palabra, del enunciado del problema). El Pensamiento Lateral, saliéndose y alejándose del sí/no continuo del pensamiento "vertical" por caminos secundarios, con serenidad, suma atención y sin desánimo; para esta técnica De Bono creó incluso una palabra fetiche: el terrible "Po".

\subsection{Métodos de reestructuración}

El Análisis Morfológico, sistemas de combinaciones de los que el más utilizado es las Matrices de Combinación (llamadas de Invención), Los complejos Organigramas Dinámicos. Los Diagramas de Sucesión. Las Listas de Ponderación.

\subsection{Las técnicas de aparición de "ideas"}

Pero para "rellenar" los renglones de estos procedimientos es preciso utilizar técnicas de hiperproducción de ideas. Quizás el famoso (pero realmente poco conocido) BraínStorming (Tormenta de ideas o Lluvia de ideas), una técnica que sobrevive, evolucionando consistentemente, desde 1937 y cuyos principios (que son los 
primeros principios formulados de la Creatividad moderna) son:

- La fase de ideación ha de estar totalmente exenta de evaluación o de crítica, en cualquiera de sus formas; están absolutamente prohibidas, en esta fase. Posiblemente, éste fue el gran descubrimiento de Osborn: separar la ideación de la aceptación o el rechazo, incluso de los menores signos de ello, Insistamos: una reunión no es un BrainStorming a menos que se destierre totalmente de ella el menor síntoma de consideración de las ideas que se vayan produciendo.

- El grupo debe ser desjerarquizado.

- Toda ocurrencia -todo lo que nos venga a la mente consciente-, por absurda o ridícula que pudiera parecemos (sí nos permitiéramos juzgarla), debe aportarse. Las risas de los otros, a las que debe unirse la nuestra, son un homenaje porque...

- ...la ocurrencia disparatada y el disparate inconsciente han de ser especialmente bienvenidos; son rompedores y a menudo muy sugerentes indicadores para otras ocurrencias.

- Lío sólo "se puede", sino que debe ser considerado tan inevitable como deseable, transformar ideas de los demás y relanzarlas, aunque sólo sea ligeramente cambiadas, 0 no, absolutamente iguales, lío importa. Nadie va a hacerlo notar.

\section{- Cantidad es calidad}

En el BraínStorming incluso las primeras sesiones de la fase posterior de evaluación pueden ser de transformación y producción de nuevas ideas. Hay un moderador y un "scriptf". El moderador (palabra evidentemente inadecuada en este caso), "líder" (también inadecuada), inductor nexialista, catalizador o catalista, puede -al disminuir la fluidez de ideación — provocar la aparición de más y más ideas haciendo 
leer espaciadamente las ideas anotadas, "apretando gatillos", en sesiones de disparo (por ejemplo, los participantes producen listas individuales que luego leen en alta voz espaciadamente, estimulando así a los demás, que "disparan" más ideas, asociadas o suscitadas, o nuevas; esto se hace una y otra vez). También suele pedir ideas descabelladas, que pueden anotarse aparte y utilizarse luego como "gatillos", o ideas "imposibles (¿?) pero deseables", etc. El nexialista provoca asimismo la cantidad: "Tenemos ya 87 ideas; lleguemos al centenar". "Estamos en un promedio de siete ideas por persona; lleguemos a diez", etc.

\section{Nuevamente, la importancia de las formas creativas}

Pero otras Técnicas básicamente grupales como la Sinéctica (etimológicamente, combinación de elementos heterogéneos, original síntesis del BraínStorming y la fantasía) han aportado otras inapreciables formas creativas al diálogo, a la comitología, a la Comunicación:

- La escucha activa. Es decir, proporcionando feed-back (retroalimentación) al interlocutor, dándole la seguridad de que se le está escuchando pero también de que se está captando la esencial de lo que va diciendo, permitiéndole desarrollar su idea hasta posibilidades que él mismo no podía esperar. Es la actitud interrogativa, la mayéutica socrática (Recuérdese que la madre de Sócrates era comadrona y él afirmaba haber aprendido de ella): "Así que usted dice que...", "Entiendo que su idea es...", etc. Lo que son, muchas veces, paráfrasis.

- Las paráfrasis, utilizadas en la Escucha Activa, son reinterpretaciones en las que lo oído se reformula con ayuda de la propia experiencia (pero secundariamente, para no tomar el papel de nuestro interlocutor). Aun cuando la paráfrasis es inadecuada sirve para la eficacia del diálogo.

- Las evaluaciones constructivas. 
- La repregunta, animando al interlocutor a reformular su pregunta de modo que exprese un nuevo modo de considerar el problema: "¿Quiere usted decir que....". Las simples preguntas separan; las redefiniciones integran.

- La respuesta fragmentada, que parte de las bases de que toda idea es útil, si se depura de sus aspectos negativos o sobrantes, y de que los elementos no claramente positivos son como nuevos subproblemas. Es algo así:

La idea tal como se ha expuesto

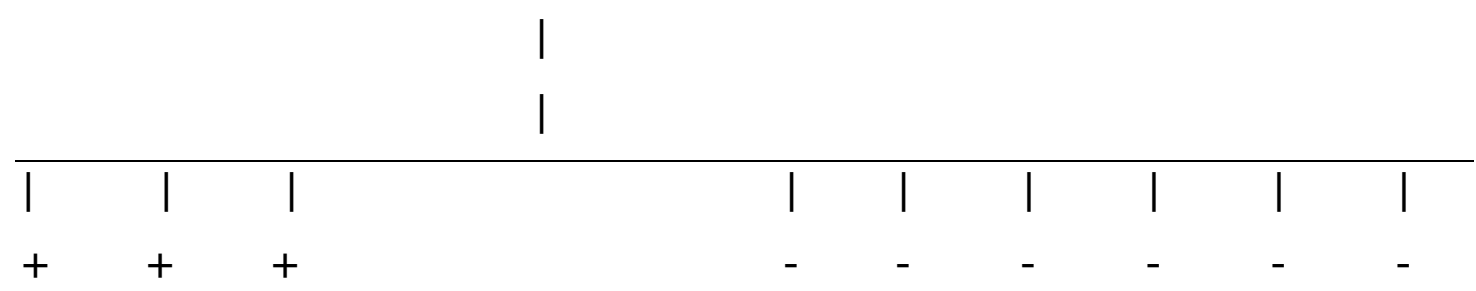

Elementos que parecen útiles

Elementos que "necesitan desarrollo"

\section{La redefinición de Europa y la tecnología de la creatividad}

- El Problem Solving (Solventar problemas), nos ha enseñado que hay que partir de la base de que no existe un "problema", más o menos aislado, sino, siempre, una situación problemática, a la que acercarse y dentro de la cual orientarse. Así, en esta Técnica, puesta a punto por el profesor Parnés, de la Universidad de Standford, primero hay que reunir los hechos, docenas, centenares; evaluarlos, depurarlos, agruparlos, y luego hallar las causas de cada uno ("docenas, centenares"...). Evaluarlas, depurarlas, agruparlas, utilizar la respuesta fragmentada, trabajar (con ayuda de un ordenador, naturalmente). Luego construir planteamientos, posiblemente muchos más de uno para cada "causa"; evaluarlos... Ahora, producir soluciones, muchas, para cada planteamiento y, a través de la misma rutina,' llegar a las aceptaciones y con ellas preparar una síntesis de superación, un mapa con 
caminos evidentes.

- También la Aplicación ha de ser considerada una situación problemática que someter a tratamiento creativo.

- La ingeniería de todas las Técnicas Grupales nos muestra que no es prudente la relación entre miembros del grupo en lo que respecta a este trabajo. Debe ser individual porque, si no, dos participantes serían en realidad sólo 1,1 ó 1,3 a lo sumo. La interacción está garantizada por el método.

- La Biónica nos habitúa a buscar en las estructuras de la Naturaleza (la fauna, la flora), de la Vida, soluciones analógicas para problemas de mecanismos o sistemas.

- El Método Delphi o Delfos, de la Rand Corporation. nos enseña a acercar, paulatina y fríamente, nuestras posiciones; especialmente, las evaluativas y las prospectivas (¿recordaremos ahora que Agenor, el padre de Europa, envió a Cadmo, uno de sus otros hijos y precisamente el que nos enseñó el alfabeto y el secreto de la fundición de los metales, a . Delfos, a preguntar al oráculo ¿"Dónde estaba Europa", la raptada, la inencontrable Europa?).

Sí, hay muchas técnicas. ¿Cuál o cuáles utilizar y en que casos? Todas; cada una en su momento, integrándolas ya espontáneamente. Del mismo modo que un mecánico tiene sus herramientas a mano, todas las posibles, cuantas más y más diferentes mejor.

\section{La redefinición de Europa}

Si queremos emprender la redefinición de Europa hay quizás que empezar por dejar de llamarla el "viejo" continente, porque sus carencias y su inconsistencia no son propios más que de la infancia. Y la Historia es la de nuestros antepasados, no la 
nuestra; de modo que no hemos de tomar de ella nada "por supuesto".

Al redefinir, habremos de cuestionarnos, por ejemplo, si nuestros maestros generan educación; si nuestros médicos, salud; si nuestros militares, patriotismo; si nuestros sindicatos, empleo y solidaridad; si nuestros impuestos, "salud pública".

Habremos de mantenernos generalistas, sea cual sea nuestra especialización. Y, en este orden de cosas, cuidado con las explicaciones de los "expertos". Ya sabemos que estamos en un globo libre perdido en la niebla; lo que queremos saber es dónde está el globo y cómo llevarlo donde nos propongamos.

Muchos políticos actuales, por su parte, parecen haber invertido el proceso creativo. Ellos parten frecuentemente de la presunta "Solución" y la hacen promesa electoral o revolucionaria. Siguen, hacía atrás, por la simplificación o reduccionismo a uno o dos dogmas políticos simples. Viene luego el planteamiento burocrático, dotado con enormes y siempre insuficientes fondos de funcionamiento, con la inevitable presión sobre los impuestos (otra vez llamados así, como en los tiempos en que al menos existía Bobin Hood; no ya en general contribución). Y, al fin, el problema, el Problema instalado, el problema ocupando el lugar final de la solución. El Problema siendo "la Solución".

Los políticos deben poner la nueva Tecnología al servicio de la continua adaptación, rectificación y realización de la Utopía.

Y, en cualquier caso, deben surgir los nexialistas, los catalistas, de la Sociedad. La Creatividad ha de popularizarse. Ser - puesto que lo es - la base de la Educación, incluso de los juegos de niños y adultos. $Y$ deben surgir grupos creativos por toda Europa, los Grupos Creativos de Europa, alrededor de periódicos, de departamentos de Universidades, de Fundaciones, de entidades culturales y sociales como ésta que hoy nos ha convocado, Comunicaciones. Publicaciones. i"Enciclopedia"! ¿Nos damos 
cuenta de que podemos, si no, estar alumbrando una Europa de funcionarios?

¿Es que aun no ha llegado el momento de otro Siglo XVIII, otro renacimiento, un nuevo criticismo, otro neoclasicismo, la ilustración de la Creatividad, las /uces augúrales? Otra época clásica; es decir, normativa (No precisamente "legislativa", obligándonos a vivir de favor, a disposición del Poder).

¿Será nuestra generación capaz de dar al Mundo y a la Historia la ya inaplazable "Declaración de los Deberes del Hombre y del Ciudadano"?

Por último, estemos tan conscientes como Guilford de que "el desenlace de nuestra civilización depende del resultado de la carrera disputada entre la educación creativa y la catástrofe".

\section{5. "Reunión en la cumbre"}

Existe una Técnica Creativa llamada Summit, "cumbre", puesta a punto en nuestro pais. En ella, los participantes emulan, cada uno, a un gran hombre o una gran mujer que conoce en cierta medida y admira como Maestro; es decir, adopta - sin que los demás sepan cuál- la supuesta mentalidad de un personaje histórico, científico, literario, artista, antiguo profesar, el padre; alguien al que admira y que conoce bien, porque lo haya estudiado, leído a fondo o conocido personalmente. Hay un primer momento de meditación en silencio para compenetrarse cada uno con su héroe ("hijo de dios y de mortal") y estas meditaciones ("recordaciones" o "evocaciones", más bien) se repiten en cualquier momento de la reunión, a petición de cualquier participante que sienta que "está perdiendo a su héroe".

A continuación, se produce una especie de BrainStorming, quizás más lento al principio. Lo realmente diferente es que no debe "hablar" el participante sino su héroe; es decir, el participante intuye más y más automáticamente que ocurrencias 
propondría su personaje, de estar allí, sin permitirse sobreactuar ni perder la concentración intentando averiguar quiénes son los demás. Los resultados son fascinantes, parecen imposibles.

Pues bien: no olvidemos convocar a esta Redefinición a tantos hombres y mujeres excepcionales que aquí nacieron y a los que no siempre se les permitió morir en Europa, Saludémoslos, mientras llegan a reunirse con nosotros.

Yo saludo a Johann Volfang Goethe, en Estrasburgo y en Fránkfurt. A Albert Einstein, en Gotinga y en Praga. A José Ortega y Gasset, en Marburgo y en Madrid. A Pablo Ruiz Picasso, en Barcelona y en París. A Martín Heidegger, siempre en Friburgo (algo debieron tener de grandes los tiempos en que nombrábamos en nuestras lenguas a las ciudades universitarias de toda Europa). A Salvador de Madariaga, en Londres y en Ginebra. A Carlos Marx, en Colonia y en Londres. A Pau Casáls, en Prades (nuevo Tántalo, al borde de nuestra frontera) y en las Naciones Unidas. A Francisco de Goya, en Aranjuez y en Burdeos.

A Goethe, que dijo: "Emprended todo lo que hayáis soñado que podéis hacer."

A Einstein, que dijo: "La imaginación es más importante que el conocimiento."

A Ortega, quien escribió, es cierto: "Yo soy yo y mi circunstancia", pero acabó la frase (que, si no, está incompleta, hasta parece querer decir lo contrario y de hecho es utilizada así en apoyo de la irresponsabilidad) "y si no la salvo a ella no me salvo yo."

A Picasso: "Yo no busco, encuentro".

A Heidegger "Dependemos del futuro; es a partir de éste que tienen sentido el presente y el pasado". 
A Madariaga, que dijo que el único sinónimo que conocía a la palabra "libertad" era respeto, antes de que los japoneses "nos confesaran que su secreto es la delicadeza en las relaciones creativas".

A Marx, quien exclamó que "no se trata de "interpretar" sino de transforma"r.

A Casáls, explicando en las Naciones Unidas el inicio del renacimiento de la democracia europea.

A Goya, que grabó la injusticia y retrató la decadencia, en tanto proclamaba tanto política como plásticamente la Libertad.

A Friedrich Nietzsche, que dijo "La patria no es la tierra de los padres ('vaterland') sino la tierra de los hijos ('kinderland')", lo que tiene ahora para nosotros una clara lectura en el tiempo.

Porque Europa, o no existe -lo que es una posibilidad, que sea sólo "un continente"o es nuestra patria.

\section{Bibliografía}

DE BONO, Edward (1996). Lógica fluida: una alternativa a la lógica tradicional. Paidós Ibérica. Barcelona.

DE BONO, Edward (1997).Seis sombreros para pensar. Gránica. Barcelona.

DE BONO, Edward (1998). El pensamiento lateral: Manual de creatividad. Paidós Ibérica. Barcelona. 
DE BONO, Edward (1998). Manual de la sabiduría: nuevas técnicas para agilizar la mente y potenciar la creatividad. Paidós Ibérica. Barcelona.

DE BONO, Edward (1999). El pensamiento creativo: el poder del pensamiento lateral para la creación de nuevas ideas. Paidós Ibérica. Barcelona.

MICHALKO, Machael (1999). Thinkertoys. Gestión 2000. Barcelona.

MUÑOZ ADÁNEZ, Alfredo (1994). Métodos creativos para organizaciones. Eudema. Madrid.

OSBORN, Alex F. (1997). Imaginación aplicada. Velflex. Madrid.

PLANA PUJOL, Julián (1988). Creatividad en la gestión. Cuadernos ESCA de la CECA. Madrid.

THOMPSON, Charles (1994). La gran idea. Gránica. Barcelona.

VV.AA. (1999). Crónicas de Innovación. Ediciones de Minessota Main Minning -3M-. Madrid. 